\title{
Field observational studies on circadian activity pattern of Oecophylla longinoda (Latreille) (Hymenoptera: Formicidae) in relation to abiotic factors and mango cultivars
}

\author{
Jean-François VAYSSIERES ${ }^{1 *}$, Antonio SINZOGAN $^{1,2}$, Sam KORIE $^{3}$, \\ Appolinaire ADANDONON ${ }^{1}$ and Seidou WOROU ${ }^{1}$ \\ ${ }^{1}$ CIRAD-Persyst, UPR HortSys, IITA, 08 BP 0932, Cotonou, Benin. Tél. (229) 21.35.01.88 \\ ${ }^{2}$ Université d'Abomey Calavi, Faculté des Sciences Agronomiques; 01BP526 Cotonou, Bénin. \\ ${ }^{3}$ IITA-Ibadan, IITA Ltd., Carolyn House, 26 Dingwall Road, Croydon CR9 3EE, UK. \\ *Corresponding author,E-mail: j.vayssieres@cgiar.org
}

\begin{abstract}
Field observational studies on circadian activity pattern of Oecophylla longinoda (Latreille) were carried out during two consecutive years in a mango orchard of the Sudanian zone of Benin. Preliminary results show that circadian activity of weaver ants is continuous although diurnal activity is greater than nocturnal activity. The consistency of the pattern suggests circadian internal clock regulation through light, temperature and humidity as its zeitgeber primary elements. Seasonal periodicity seems not to act on weaver ant activity between dry, rainy and harmattan seasons. Laboratory experiments now need to be implemented to check and complete these field results, and to screen for these three abiotic factors and others of potential relevance. Cultivars with thin foliage and modest canopies sheltered more nests than those with thick foliage and a dense canopy. This study raises practical issues on the use of biological control agents to improve weaver ant management and these are discussed.
\end{abstract}

(c) 2011 International Formulae Group. All rights reserved.

Key words: Benin, circadian activity pattern, Oecophylla longinoda, light, temperature, humidity, zeitgeber, weaver ant management.

\section{INTRODUCTION}

Ants have a major influence in many habitats in view of their abundance, their stability as populations and their feeding habits. Ant species make use of circadian clocks to occupy specific territories at different times. In Africa, habitat such as tree crop plantations is occupied by 'territoriallydominant' arboreal ant species (Hölldobler, 1983; Parr and Gibb, 2010) like Oecophylla longinoda (Hymenoptera: Formicidae). These species are characterized by populous colonies, the ability to build large and/or polydomous nests and a highly developed intra- as well as interspecific territoriality (Crozier et al., 2009) that causes their territories to be distributed in a mosaic pattern in tree canopies (Majer, 1972; Dejean et al., 1994; Blüthgen and Stork, 2007). In fruit plantations, the manipulation of the ant mosaic can be utilized in pest control (Majer, 1976). All the territorially-dominant arboreal ants studied exhibit a very efficient predatory behavior. To illustrate their predatory 
efficiency, Dejean (1990) recorded that a colony of $O$. longinoda comprising 12 nests may make about 45,000 captures of prey per year. But ants also exhibit indirect mechanisms that invoke the detection by herbivores of the territories of hostile ants (Offenberg et al., 2004; Adandonon et al., 2009; Van Mele et al., 2009) in addition to direct mechanisms, including predation or deterrence of herbivores during direct encounters.

Appropriate pest management options for fruit and nut growers in sub-Saharan Africa should be cost-effective, locally available and sustainable. The weaver ant $O$. longinoda is endemic in Africa and frequently abundant in unsprayed orchards. It has been shown to suppress fruit flies effectively on mango in Benin, as a result of which the negative perceptions of the ant held by farmers are changing (Van Mele et al., 2007; Sinzogan et al., 2008). Consequently it has been integrated as a component of a combination of effective, efficient and compatible control methods - the so-called "IPM package" developed by the West African Fruit Fly Initiative (WAFFI), an ongoing regional control program on the development and promotion of area-wide integrated pest management in West Africa.

Disseminating techniques on application and conservation of the weaver ant (Oecophylla longinoda) for the management of fruit flies across different geographical locations requires prerequisite knowledge of the factors that help or hamper ant protection skills. The ability of ants to protect plants against pests is related to their activity pattern (foraging to prey and foraging/patrolling to leave cues on fruits). Dejean (1990) noted several different conclusions from studies which investigated the activity pattern of Oecophylla species. For $O$. longinoda that hunts by sight (Dejean, 1986), light intensity is a crucial factor, although other physical factors such as temperature and humidity play an important role in Oecophylla activities. Robertson (1988) hypothesized that levels of ant predation on insect pests can be altered by seasonal changes. Yet, factors influencing the activity patterns of $O$. longinoda species remain almost undocumented, especially for the environmental conditions of West Africa where WAFFI is promoting its IPM package. Study of the circadian activity pattern of the weaver ant $O$. longinoda and the influence of certain factors is of great ecological interest because it affords an opportunity to clarify some elements of the spatio-temporal distribution of weaver ant species at the scale of both the tree and the orchard.

We could also underline that the Asian ant species, Oecophylla smaragdina Fabricius, is largely used as an effective biological control agent in West Asia on citrus crops (Van Mele and Cuc, 2000; 2003) and Australia on mango crops (Peng and Christian, 2004; 2005) and also cashew crops (Peng et al., 1995).

The reported study is part of an ongoing regional control program for the development and promotion of area-wide integrated pest management in West Africa. It took place on a relatively large scale in the Borgou department, the most important mango-producing area of Benin that encompasses in the best mango production zone of West Africa, i.e. bounded from 8 to 14 degrees north latitude (Vayssières et al., 2008).

The objective of this study was to investigate: i) circadian activity pattern of adults (workers) of $O$. longinoda; ii) influence of seasons and environmental conditions on ant behavior and activity; iii) influence of different mango cultivars on ant activities. We discuss the significance of the findings for introduction/establishment and management of $O$. longinoda in mango orchards because of its positive contribution in mango orchards.

\section{MATERIALS AND METHODS Study site}

The study site was a mango orchard of 40 ha located $\left(09^{\circ} 37^{\prime} 01^{\prime \prime N} / 02^{\circ} 67^{\prime} 08^{\prime \prime} \mathrm{E}\right)$ in Parakou region, Borgou department, in the Sudanian area of Benin. Figure 1 depicts monthly averages for rainfall and temperature 


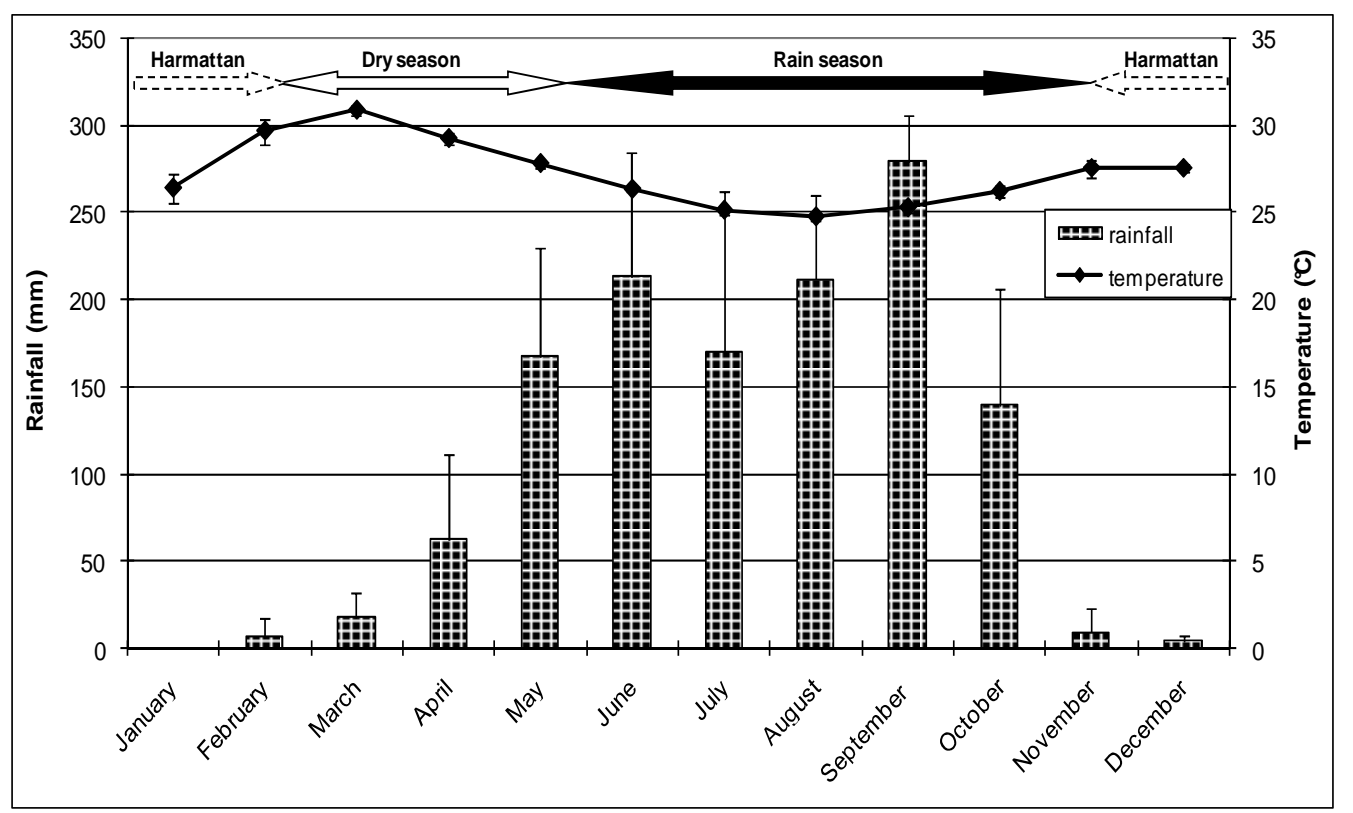

Figure 1: Monthly average rainfall and temperature in the studied mango orchard (Korobourou) 2007 to 2009 (meteorological data from Asecna database).

from 2007 to 2009 in Borgou department, which has three distinct seasons: 1) dry season (March-May); 2) rainy season (JuneOctober); and 3) harmattan season (November-February). While the nature of the dry and rainy seasons is self-evident, the harmattan season is characterized by dry and dusty winds blowing from the North East to South West in West Africa. They bring temperate temperatures during the day, but cold ones during the night and a very low relative humidity from the middle of November to the end of February. So, we could expect the harmattan season to influence ant behaviour.

The orchard was divided into four blocks, each having a good abundance of weaver ant colonies and containing at least one of the main mango cultivars [Dabshar Drahnet, Eldon, Gouverneur (=Amélie) and Kent] that are the most commonly cultivated in Borgou department. A total of 208 mango trees in this orchard were sampled, comprising 52 trees of each of the four mango cultivars. These trees were 29 years old and quite homogeneous in height, populating the orchard with an average of 100 trees/ha at a $10 \mathrm{~m} \times 10 \mathrm{~m}$ density. Weaver ant activity was therefore studied over consecutive years (from November 2007 to November 2009) on the four different cultivars. Preliminary test of different methods to monitor circadian activity pattern of $O$. longinoda was carried out during a six-month period from May to October 2007.

\section{Monitoring of the circadian pattern of activity}

The activity of an ant colony is the sum of all of the separate behavioral acts performed by its constituent members. These behaviors can be grouped by location: inside and outside the nest. This study determined the variation in the weaver ant activity over $24 \mathrm{~h}$ by concentrating on activity outside the nest. The intensity of extra-nest activity by ants is expressed through the density/abundance of ants outside the nest. Observations were made on dry days after we noted that weaver ants mostly returned to their 
nests when it rained and hardly ever sheltered under twigs and leaves.

The method used to determine the abundance of the ants was inspired by that (Branch Method) described by Peng and Christian (2004). This method consists of counting the number of ants that display on the main branches. Both for convenience and to homogenize the observations, observations were done on the area of the tree corresponding to the height reached by the observer with outstretched arm $(\sim 2.40 \mathrm{~m})$. Ants present beyond this limit were not counted. A score was assigned to each main branch as follows: if no ants are observed the branch is noted at 0 , if there are from 1 to 10 ants the branch is noted $1 / 2$, finally if there are more than 10 ants the branch is noted as 1 . The abundance (in percentage) is then determined by adding the scores divided by the number of main branches of the tree multiplied by 100 .

Eight colonized trees (two per block) were chosen haphazardly. Data were collected on one day a fortnight on every hour from 7:30 AM to 6:30 AM on the following day for two years. Physical data (temperature and relative humidity) were recorded concurrently every hour. The duration of moon light was recorded from 7:30 $\mathrm{PM}$ to 6:30 $\mathrm{AM}$ the following day.

\section{Statistical analysis}

To analyze data, hours of the day were grouped in six time periods: 1. Early Morning (5:30 AM to 8:30 AM); 2. Mid_Day (9:30 AM to $11: 30$ AM); 3. Early Afternoon (12:30 $\mathrm{PM}$ to $2: 30 \mathrm{PM}) ; 4$. Late Afternoon (3:30 PM to $6: 30 \mathrm{PM}) ; 5$. Evening (7:30 PM to $10: 30$ PM); 6. Night (11:30 PM to 4:30 AM). Likewise, months were grouped in three main seasons 1) dry season (March-May), 2) rainy season (June-October), and 3) harmattan season (November-February). Brightness was grouped in three main categories: the period from 7:30 AM to 6:30 PM is considered as 1) Day-light; from 7:30 PM to 6:30 AM, the presence of the moon is classed as 2) Moon- light, while the absence of the moon is considered as 3) No-light.

Circadian effect was examined for variation among the three categories of light, six time periods, three seasons and two years in a mixed model analysis of variance (SAS 2003). We did multivariate (PCA) analysis supported by Pearson correlation analysis to understand the ANOVA results as influenced by physical factors and better interpret the relationship. Interaction could be analysed by correlation coefficient and visualized by biplots.

Average ants abundance was obtained over the sample trees since physical measurements (temperature, humidity, etc.) were taken on hourly basis. Furthermore, the data were $(x+0.5)^{1 / 2}$ transformed before analysis to stabilize the variance. Linearmixed-effects model ANOVA (PROC MIXED) in SAS was used to assess treatment differences, with Season, TimePeriod, and Light as fixed effects factors and Time (or hours) nested within TimePeriod as the random effects factor. Means separation, for significant factors and interactions, was performed using the SAS LSMEANS pairwise t-test comparison at $\mathrm{P}<0.05$.

\section{RESULTS}

Circadian activity pattern and effect of temperature and humidity

Ant activity outside the nest was uninterrupted throughout the day (24h) with a significant variation among day time periods (P < .0001) (Fig. 2). Activity was lowest in the night (11:30 PM to 4:30 AM), followed by a significant rise at early morning (5:30 AM to $8: 30 \mathrm{AM})$ then a further significant rise (9:30 AM to 11:30 AM) to a midday peak. From midday to late afternoon (9:30 AM to 6:30 PM time period) activity was relatively constant, followed by a rapid evening decrease (7:30 PM to 10:30 PM). The polynomial tendency curve of the day's activity is unimodal with the peak at early afternoon (12:30 PM to 2:30 PM) (Fig. 2). 


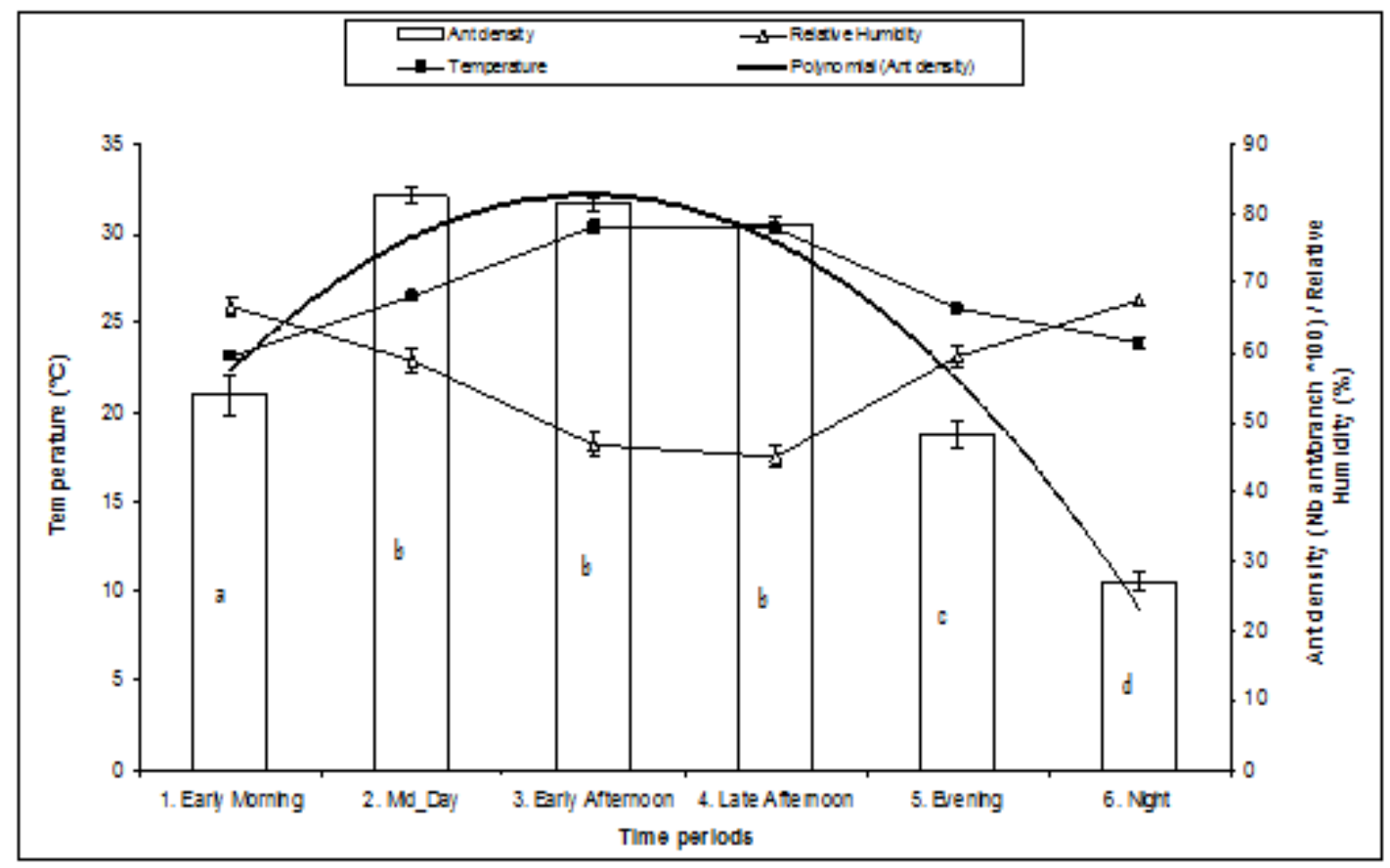

Figure 2: Mean rhythm of activities outside the nest and variation of temperature and humidity during different time periods of the day.

Each observation of the different factors (ant density, temperature and humidity) is the mean $\pm \mathrm{SE}$ of observations made hourly from 7:30 AM to 6:30 AM the following day, carried out on a fortnightly basis for two years and pooled according to the following time periods: 1. Early Morning (5:30 AM to 8:30 AM); 2. Mid Day (9:30 AM to 11:30 AM); 3. Early Afternoon (12:30 PM to 2:30 PM); 4. Late Afternoon (3:30 PM to 6:30 PM); 5. Evening (7:30 PM to 10:30 PM); 6. Night (11:30 PM to 4:30 AM). Bar charts with a different letter are significantly different $(\mathrm{P}<0.05)$. Polynomial curve line is the software-derived trend of the bar chart.

Ants are more abundant in the mid-day, early and late afternoon periods - when temperature is higher and relative humidity (RH) lower. They are less abundant in the evening, night and early morning. $\mathrm{RH}$ is also higher at these times and temperature is also lower (Fig. 2). Correlation analysis supports the finding that temperature is a very important abiotic factor for weaver ants. Ant activity outside the nest was positively correlated with temperature $(r=0.50, n=896$, $\mathrm{P}<0.0001)$ and negatively with RH $(\mathrm{r}=$ $0.18, \mathrm{n}=896, \mathrm{P}<0.0001)$.

\section{Effect of light}

Ant activities outside the nest were generally higher during Day-light than at night (moon or no-moon). Activities during Moon-light and Day-light times were all highly significantly different from No-light (no-moon) activities $(\mathrm{P}<0.0001)$ (Table 1). Though Day-light activities are higher than those in the night (moon) periods, the difference is not significant from ANOVA ( $P$ $=0.05)$. We did not intend to subject the variables Temperature and RH to ANOVA, but their mean summaries were put alongside mean abundance to aid interpretation of any apparent trend. Table 1 shows the results of ANOVA by Light factor and mean summaries of ant densities, temperature and humidity. It was evident from the table that temperature was higher and humidity lower during the Day-light periods when ant activities were in 
fact most intense. This was not unexpected as the effects imposed by temperature and humidity factors could be confounded in Light and Time-Period factor levels.

\section{Effect of seasons}

Any relationship with seasons is not very apparent. According to the ANOVA (Table 2), the variation in ant activity is not significantly different across the following seasons 1) dry season (March-May), 2) rainy season (June-October), and 3) harmattan (November-February). Likewise, PCA analysis (Fig. 3) did not reveal any clear relationship trend for seasonal activities and physical factors, although there is slight significant difference for ant density between dry season vs. harmattan and rainy seasons for the Early Morning time period. Figure 4 depicts this early morning trend.

There was slight interaction between Season and Time Period. While there were no significant differences between seasons during day time periods, there were significant differences between seasons at night and early morning periods. Ant abundance was generally higher in the dry season than in both the harmattan and rainy seasons at night-time and early morning periods but not in day time periods.

\section{Effect of mango cultivars}

The pattern (trend) of ant abundance is significantly different for cultivars $(\mathrm{p}<0.05)$ associated with three groups (i) Eldon, (ii) Kent and Gouverneur, (iii) Dabshar Drahnet (Fig. 5). More than 50\% of ant abundance was recorded on three of the investigated cultivars (Eldon, Gouverneur and Kent) while only Dabshar had less than $50 \%$ (Fig. 5). This meant that the main branches of Eldon, Gouverneur, and Kent were patrolled hourly by more than 10 ant workers and those of Dabshar by fewer than 10 ant workers per hour.

Table 1: Variations of ant density, temperature and humidity in relation to available light.

\begin{tabular}{|c|c|c|c|}
\hline $\begin{array}{l}\text { Light } \\
\text { condition }\end{array}$ & $\begin{array}{c}\text { Ant density } \\
(\mathrm{Nb} \text { ant/ branch } * 100) \pm \\
\mathrm{SE}\end{array}$ & $\begin{array}{c}\text { Mean temperature }\left({ }^{\circ} \mathrm{C}\right) \\
\pm \mathrm{SE}^{* *}\end{array}$ & Mean RH (\%) \pm SE** \\
\hline Day-light & $77.46 \pm 0.86 \mathrm{a}$ & $28.20 \pm 0.18$ & $51.83 \pm 0.92$ \\
\hline Moon-light & $48.98 \pm 2.36 \mathrm{a}$ & $24.71 \pm 0.28$ & $63.94 \pm 1.73$ \\
\hline No-light & $32.28 \pm 1.40 \mathrm{~b}$ & $24.16 \pm 0.20$ & $66.13 \pm 1.16$ \\
\hline Probability & $\mathrm{P}<0.05$ & & \\
\hline
\end{tabular}


J. F. VAYSSIERES et al. / Int. J. Biol. Chem. Sci. 5(2): 790-802, 2011

Table 2: Variations of ant density in relation to seasons during different time periods of the day.

\begin{tabular}{|c|c|c|c|}
\hline Time Period & $\begin{array}{c}\text { Harmattan season } \\
\text { [November-February] } \\
\text { Mean } \pm \text { S.E. }\end{array}$ & $\begin{array}{c}\text { Dry season } \\
{[\text { March-May] }} \\
\text { Mean } \pm \text { S.E. }\end{array}$ & $\begin{array}{c}\text { Rain season } \\
\text { [June-October] } \\
\text { Mean } \pm \text { S.E. } \\
\end{array}$ \\
\hline $\begin{array}{l}\text { Early Morning } \\
\text { (5:30 AM to 8:30 AM) }\end{array}$ & $41.93 \pm 5.38 \mathrm{bB}$ & $69.92 \pm 4.10 \mathrm{bA}$ & $48.85 \pm 4.01 \mathrm{bB}$ \\
\hline $\begin{array}{l}\text { Mid Day } \\
\text { (9:30 AM to } 11: 30 \mathrm{AM})\end{array}$ & $82.37 \pm 2.49 \mathrm{aA}$ & $86.10 \pm 1.37 \mathrm{aA}$ & $80.39 \pm 2.20 \mathrm{aA}$ \\
\hline $\begin{array}{l}\text { Early Afternoon } \\
\text { (12:30 PM to 2:30 PM) }\end{array}$ & $80.88 \pm 1.44 \mathrm{aA}$ & $76.64 \pm 1.94 \mathrm{abA}$ & $84.74 \pm 0.54 \mathrm{aA}$ \\
\hline $\begin{array}{l}\text { Late Afternoon } \\
(3: 30 \mathrm{PM} \text { to } 6: 30 \mathrm{PM})\end{array}$ & $77.64 \pm 1.68 \mathrm{aA}$ & $80.69 \pm 1.26 \mathrm{abA}$ & $77.70 \pm 2.16 \mathrm{aA}$ \\
\hline $\begin{array}{l}\text { Evening } \\
\text { (7:30 PM to } 10: 30 \mathrm{PM})\end{array}$ & $48.55 \pm 4.57 \mathrm{bA}$ & $49.11 \pm 3.19 \mathrm{cA}$ & $47.17 \pm 3.41 \mathrm{bA}$ \\
\hline $\begin{array}{l}\text { Night } \\
(11: 30 \text { PM to } 4: 30 \text { AM) }\end{array}$ & $27.82 \pm 3.23 \mathrm{cAB}$ & $32.40 \pm 2.07 \mathrm{dA}$ & $22.36 \pm 2.07 \mathrm{cB}$ \\
\hline
\end{tabular}




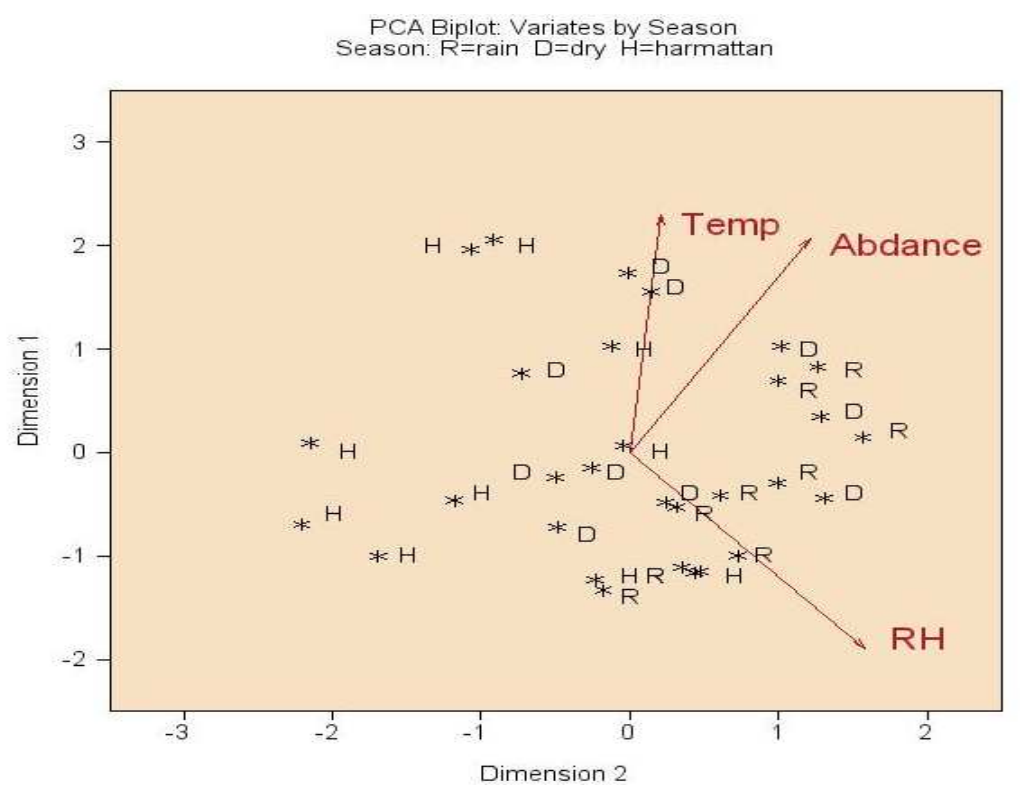

Figure 3: Biplot of a principal component analysis performed on the interaction between the activities during different seasons of the year and physical factors. Temp: temperature. Abdance: abundance. RH: relative humidity.

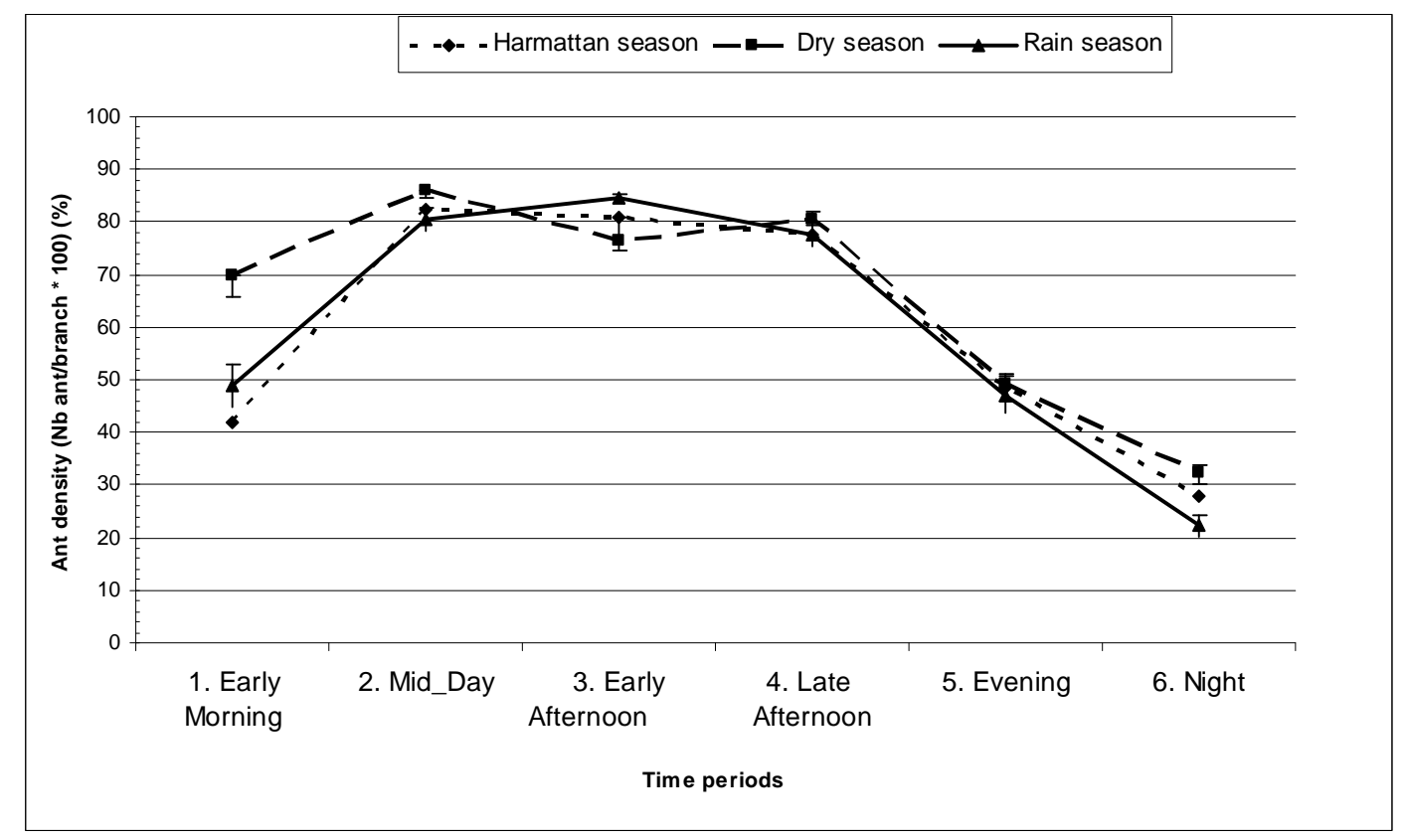

Figure 4: Comparison across season of mean ant density outside the nest.

Each observation of ant density is the mean \pm SE of observations made hourly from 7:30 AM to 6:30 AM the following day, carried out on a fortnightly basis for two years and pooled according to the following time periods: 1. Early Morning (5:30 AM to 8:30 AM); 2. Mid Day (9:30 AM to 11:30 AM); 3. Early Afternoon (12:30 PM to 2:30 PM); 4. Late Afternoon (3:30 PM to 6:30 PM); 5. Evening (7:30 PM to 10:30 PM); 6. Night (11:30 PM to 4:30 AM). 


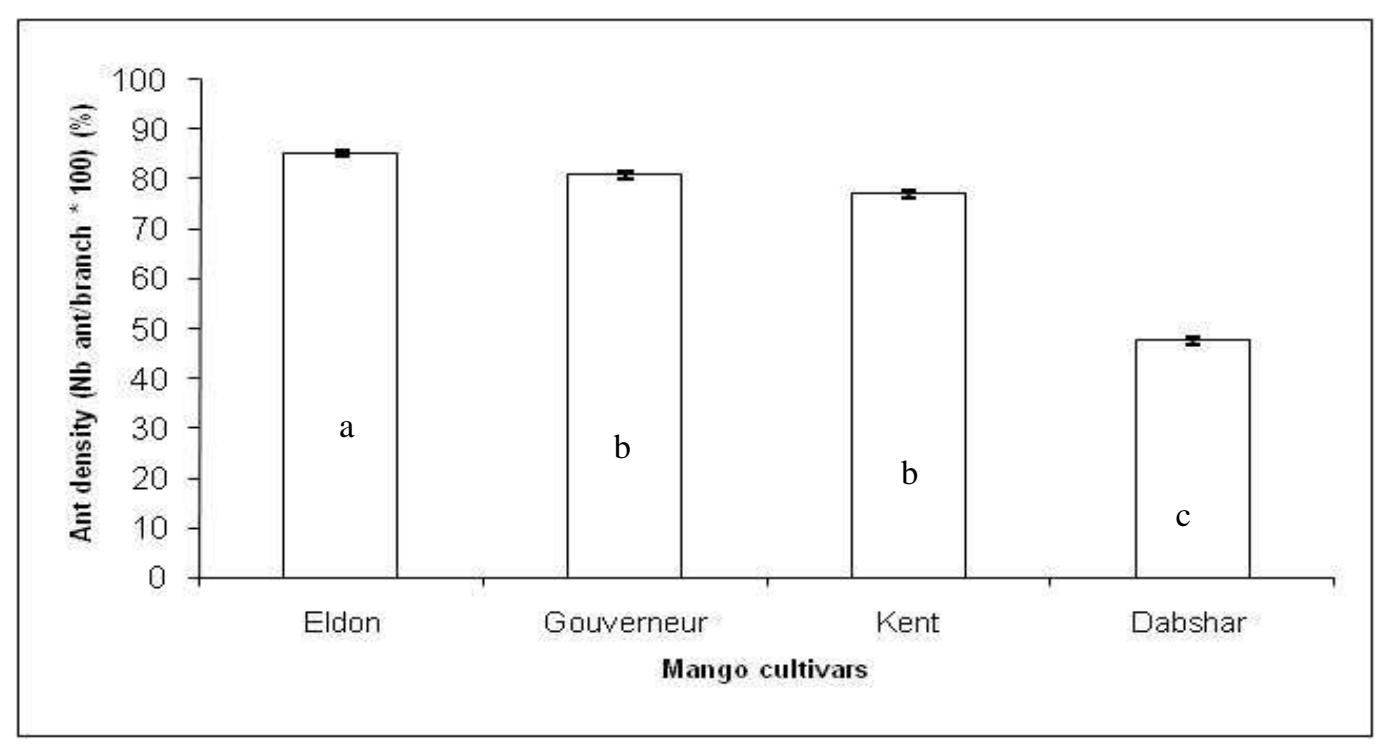

Figure 5: Mean ant density outside the nest in relation with mango cultivars.

Each observation is the mean \pm SE of observations made hourly from 7:30 AM to 6:30 AM the following day, carried out fortnightly for two years. Bar charts with a different letter are significantly different $(\mathrm{P}<0.05)$.

\section{DISCUSSION}

Ant activity is continuous throughout the day. However, daily rhythms of ant activity outside the nest, expressed through the observed density of the ants, are not homogeneous throughout the day, with diurnal activity being greater than nocturnal activity. Apparently, O. longinoda displayed a circadian pattern following the dawn and dusk rhythm, except when it was raining. According to our field observations in Benin, we can highlight a high diurnal level of activity by $O$. longinoda, due mainly to guarding, foraging and hunting activities on arthropods, and also a lower nocturnal level allied especially to guarding and rare hunting activities on nocturnal insects (termites).

Weaver ants have been reported by many authors to be primarily diurnal (Greenslade, 1971; Hölldobler, 1979) with lower night activity (Lévieux, 1978; Dejean 1990). The high level of daytime activities is probably due to the recruitment of more workers for the foraging tasks generally considered as the main extra-nest activity of ants, and primarily motivated by hunger within the nest. However, the constancy of the observed circadian pattern of activities suggests internal clock regulation with ants probably performing tasks other than (or in conjunction with) foraging, i.e. brood and callow transport, colony odor dispersal, and territorial patrolling (Lokkers, 1990). The author indicated that the circadian pattern of $O$. smaragdina did not always correlate with food intake.

One of the disadvantages of using weaver ants as a biological agent is their aggressiveness, which is not beneficial for the perception of ants, especially by the local farmers who are frequently bitten during harvest. Our investigation on circadian activities was also guided by practical issues of weaver ant management: was there any moment of the day during which ants are less active which would help determine the best time for harvesting or introducing fresh ants? Given that the day 
time (9:30 AM to 6:30 PM) is the most active period for weaver ants, it is not recommendable for harvesting - contrary to the assertion of growers that it was best to climb trees during the hot period of the day (less active period of the ant). On the other hand, by placing animal waste (such as intestines or fish) under the tree as an attractant during this period of greater ant activity, we could gather the majority of workers on the tree, thereby freeing the tree for harvest.

This study over 24 months showed that temperature, humidity and light were consistently related to the variation in weaver ant activity throughout the day. Those elements can be considered as external cues that trigger some sort of change in the weaver ant's internal clock or zeitgeber. In fact, the temporal pattern of ant activity is thought to be launched by an endogenous biological clock entrained by certain environmental cues. Light has been proved to be the primary zeitgeber of $O$. longinoda (Dejean, 1990). Temperature has been correlated to activity by many ant species (e.g. Veromessor pergandei Meyr and Pogonomyrmex californicus (Buckley): Bernstein, 1979; O. smaragdina: Lokkers, 1990). In the current study, analyzing ant activities only in relation to temperature and humidity indicates a positive correlation with temperature and one that is negative with humidity. As weaver ants generally prefer moist habitats, this negative correlation might seem inconsistent. In fact, this pattern probably reflects the negative correlation between light/temperature and humidity. With the integration of the light factor in the analysis, and despite the low temperature and high humidity at night during periods of lunar presence, ant densities were not significantly different between Day-light and Moon-light periods although day time period densities showed a trend towards higher values. A number of factors therefore intertwine to act on the internal clock of the weaver ant. Dejean (1990) previously observed the positive influence of moonlight on the activity rhythm of $O$. longinoda in Central Africa (Democratic Republic of Congo and Cameroon).

It appears that seasons do not act on the circadian pattern of $O$. longinoda in the relative seasonal environment of the wet tropics (south Sudanian zone) in central Benin. It seems that tasks restricted to outside the nest, including foraging, patrolling, guarding and defending (Lokkers, 1990), are not in the range of weaver ant responses governed by seasonal biological periodicity, but are influenced instead by circadian clock (Denlinger et al., 2001; Danks, 2003). Seasonal effect on the weaver ant cannot be determined only from observation of outside-the-nest tasks as in our survey, but we nevertheless noticed that weaver ants were more active during the flowering and fruiting period of mangoes because of higher abundance of prey (mainly insects). Manipulative field experiments observing inside the nest would be required before presenting a more definitive opinion on seasonal effects.

It would be interesting to carry out the same experiments on $O$. longinoda in the north of the Sudanian zone adjoining the Sahelian zone where abiotic factors are highly different among seasons. We can wonder if the stronger harmattan wind can trigger any response from weaver ants from November to February. The monitoring of spatial repartition of ant nests all the year round could provide some interesting results.

Mango cultivars exhibited significant differences for weaver ant activities in our study. Cultivars such as Eldon with its thin foliage, i.e. low leaf area index (LAI) and high diffuse non-interceptance (DNI) based on the fraction of sky which can be seen from the canopy - (Rajan et al., 2001), sheltered an abundance of nests, while those with thick foliage like that of Dabshar sheltered few nests (Vayssières et al., unpublished). This could be explained by the fact that Oecophylla ants have light as a crucial factor for colonizing and building 
nests with living leaves, so suitable vegetation should not be deciduous. Leaves must exceed a certain size and leaves must be strong but flexible like those of the Eldon cultivar. To introduce weaver ants in virgin orchards, one should select trees with thin foliage but also strong and flexible leaves that will facilitate speedy and secure establishment of the colony. However, Oecophylla can adapt the foliage of most trees for nest building (Greenslade, 1972; Van Mele and Cuc, 2003). In Borgou, we have begun an inventory of more than 30 different species of trees, shrubs and lianas that host nests of Oecophylla (Vayssières et al., unpublished). Besides canopy issues, the choice of host plant for nest building might also depend on the ability of the plant to support suitable Homoptera clusters.

\section{Conclusion}

O. longinoda shows consistency and also an important plasticity in its natural circadian pattern of activity. Daily current cues (temperature, humidity and light) are interrelated to act on the internal clock of weaver ants possessing a strong mutual motivation between individuals. But other elements not taken into account in this study could also play a role in the circadian activity pattern. This circadian system also integrates many other elements, including current signals, stored information, timing mechanism, etc. for the appropriate management of activities. Circadian pattern investigation contributes to building a general picture of the roles of ants in local agro-ecosystems, especially pertinent to improvement of the management of weaver ants for use as a biological control agent.

\section{ACKNOWLEDGEMENTS}

We would like to thank Issa Ouagoussounon, Soumanou Modjibou and Renaud Socié for their technical help. We are also grateful to the World Bank and the World Trade Organisation for funding. We thank CIRAD and IITA-Cotonou for their support during these last years where weaver ants were studied in Benin. Many thanks also to David Millar for reviewing an earlier version of the manuscript. We also thanks most sincerely three unnamed reviewers who read this document and made a number of relevant remarks

\section{REFERENCES}

Adandonon A, Vayssières J-F, Sinzogan A, Van Mele P. 2009. Density of pheromone sources of the weaver ant Oecophylla longinoda affects oviposition behaviour and damage by mango fruit flies (Diptera: Tephritidae). International Journal of Pest Management, 55(4): 285-292.

Bernstein RA. 1979. Schedules of foraging activity in species of ants. J. Anim. Ecol., 48: 921931.

Blüthgen N, Stork NE. 2007. Ant mosaics in a tropical rainforest in Australia and elsewhere: A critical review. Aust. Ecol., 32: 93-104.

Crozier RH, Newey PS, Schlüns H, Robson SK. 2009. A masterpiece of evolution Oecophylla weaver ants (Hymenoptera: Formicidae). Myrmecological News, 13: 57-71.

Danks HV. 2003. Studying insects photoperiodic and rhythmicity: components, approaches and lessons. Eur. J. Entomol., 100: 209-221.

Dejean A. 1986. Predation by the ant Oecophylla longinoda in Zaire. $37^{\text {th }}$ Annual AIBS Meeting, 10-14 August 1986, Amherst, Massachusetts. ATB Abstracts, p. 16.

Dejean A. 1990. Circadian rhythm of Oecophylla longinoda in relation with territoriality and predatory behaviour. Physiological Entomology, 15: 393-403.

Dejean A, Akoa A., Djieto-Lordon C,Lenoir A. 1994. Mosaic ant territories in African secondary rain forest (Hymenoptera: Formicidae). Sociobiology, 23: 275-292. 
Denlinger DL, Giebultowicz JM, Saunders DS. 2001. Insect Timing: Circadian Rhythmicity to Seasonality. Elsvier: Amsterdam.

Greenslade PJM. 1971. Interspecific competition and frequency changes among ants in Solomon Islands coconut plantations. J. Appl. Ecol., 8: 323-352.

Greenslade PJM. 1972. Comparative ecology of 4 tropical ant species. Insectes sociaux, 19: 195-212.

Hölldobler B. 1979. Territoriality in ants. Proc. Am. Phil. Soc., 123: 211-218.

Hölldobler, B. 1983. Territorial behavior in the green tree ant (Oecophylla smaragdina). Biotropica, 15 : 241-250.

Lévieux J. 1978. La nutrition des fourmis tropicales : V-éléments de synthèse. Les modes l'exploitation de la biocénose. Insectes sociaux, 24: 235-260.

Lokkers C. 1990. Colony dynamics of the green tree ant (Oecophylla smaragdina Fab.) in aseasonal tropical climate. $\mathrm{Ph} . \mathrm{D}$ thesis, James Cook University of Queensland, p. 301.

Majer JD. 1972. The ant-mosaic in Ghana cocoa farms. Bull. Entomol. Res., 62: 151-160.

Majer JD. 1976. The maintenance of the ant mosaic in Ghana cocoa farms. J. Appl. Ecol. 13: 123-144.

Offenberg J, Nielsen MG, Macintosh DJ, Havanon S, Aksornkoae S. 2004. Evidence that insect herbivores are deterred by ant pheromones. Proceedings of the Royal Society of London Series B-Biological Sciences 271: 433-435.

Parr C, Gibb H. 2010. Competition and the role of dominant ants. In Ant Ecology, Lach L, Parr C, Abbott K (Eds). Oxford University Press; 77-96.

Peng R, Christian K, Gibb K. 1995. The effect of the green ant, Oecophylla smaragdina, (Hymenoptera: Formicidae), on insect pests of cashew trees in Australia. Bull. Entomol. Res., 85: 279-284.

Peng R, Christian K. 2004. The weaver ant, Oecophylla smaragdina (Hymenoptera Formicidae), an effective biological control agent of the red-banded thrips, Selenothrips rubrocinctus (Thysanoptera : thripidae) in mango crop in the Northern Territory of Australia. Int. J. Pest Management, 50: 107-114.

Peng R, Christian K. 2005. Integrated pest management in mango orchards in the Northern Territory Australia using the weaver ant, Oecophylla smaragdina, (Hymenoptera: Formicidae) as a key element. Int. J. Pest Management, 51: 149-155.

Rajan S, Kumar R, Negy SS. 2001. Variation in canopy characteristics of mango (Mangifera indica L.) cultivars from diverse eco-geographical regions. J. Appl. Hort., 3(2): 95-97.

Robertson HG, 1988. Spatial and temporal patterns of predation by ants on eggs of Cactoblastis cactorum. Ecol. Ent., 13: 207-214.

SAS. 2003. The SAS System for Windows, version 9.1 computer program. Cary, NC: SAS.

Sinzogan AAC, Van Mele P, Vayssières JF. 2008. Effects of on-farm research on local knowledge related to fruit and the weaver ant Oecophylla longinoda in orchards in Benin. Int. J. Pest Management, 54: 241-246.

Van Mele P, Cuc NTT. 2000. Evolution and status of Oecophylla smaragdina as a pest control agent in Citrus in the Mekong Delta, Vietnam. Int. J. Pest Management, 46: 295-301. 
Van Mele P, Cuc NTT. 2003. Ants as friends: Improving your tree crops with weaver ants. CABI Bioscience, p. 67.

Van Mele P, Vayssières J-F, Van Tellingen E, Vrolijks J. 2007. Effects of an African weaver ant, Oecophylla longinoda, in controlling mango fruit flies (Diptera : Tephritidae) in Benin. Journal of Economic Entomology, 100: 695-701.

Van Mele P, Vayssières J-F, Adandonon A, Sinzogan A. 2009. Ant cues affect the oviposition behaviour of fruit flies (Diptera: Tephritidae) in Africa. Physiological Entomology, 34: 256251.

Vayssières J-F, Korie S, Coulibaly $\mathrm{T}$, Temple L, Boueyi S. 2008. The mango tree in northern Benin (1): cultivar inventory, yield assessment, early infested stages of mangoes and economic loss due to the fruit fly (Diptera Tephritidae). Fruits, 63: 1-22. 